\title{
WEBSITES AND RESOURCES FOR AVIAN AND PANDEMIC INFLUENZA
}

\section{WEBSITES}

\section{Animal Health Australia}

www.animalhealthaustralia.com.au/programs/eadp/ausvetplan_home.cfm contains the Australian Veterinary Emergency Plan (AUSVETPLAN), which is a series of technical response plans that describe the proposed Australian approach to the occurrence of an exotic disease. It includes a link to the Australian disease strategy for avian influenza.

\section{Australian Government Department of Health and Ageing}

www.health.gov.au/ provides an extensive range of links to Australian Government resources and plans for national health emergencies. It includes links for pandemic preparedness, avian influenza, the Australian Health Management Plan for Pandemic Influenza, and Exercise Cumpston 06.

\section{Australian Government Department of Tourism, Industry and Resources}

www.industry.gov.au/pandemicbusinesscontinuity/ contains a range of tools to assist small businesses to prepare for a human influenza pandemic in Australia

\section{Australian Government Travel Advisory and Consular Assistance Service \\ www.smartraveller.gov.au/ contains travel advisories and bulletins to assist Australians to travel overseas safely. \\ emergencyNSW \\ www.emergency.nsw.gov.au/ is the public emergency information website of the NSW Government. It provides information about how to prepare for, deal with and recover from an emergency situation.}

\section{NSW Department of Health}

www.health.nsw.gov.au/pandemic/ provides regular updates about pandemic influenza preparedness, the current H5N1 avian influenza outbreak in birds, and information and resources for pandemic influenza planning, particularly for NSW.

www.health.nsw.gov.au/pandemic/docs/nswplan.pdf contains the whole-of-government NSW Human Influenza Pandemic Plan.

\section{NSW Department of Primary Industries}

www.agric.nsw.gov.au/reader/avian-influenza contains information and resources about avian influenza.

\section{United States Department of Health and Human Services}

www.pandemicflu.gov/index.html provides information and updates about avian and pandemic influenza from the United States Government.

\section{World Health Organization}

www.who.int/csr/disease/avian_influenza/en/index.html tracks the evolving situation with human cases of H5N1 avian influenza and provides access to both technical guidelines and information useful for the general public. It also has links to pandemic influenza pages.

www.who.int/ethics/influenza_project/en/index.html contains discussion papers that examine a wide range of ethical issues raised by a potential influenza pandemic, as well as some key documents from other international ethics centres.

\section{JOURNALS}

\section{Medical Journal of Australia}

Supplement - Preparing for an influenza pandemic. Vol. 185, No. 10, 20 November 2006.

www.mja.com.au/public/issues/185_10_201106/suppl_contents_201106.html

\section{Emerging Infectious Diseases}

Special issue: Influenza. Vol.12, No. 1, January 2006.

www.cdc.gov/ncidod/eid/vol12no01/contents_v12n01.htm 